\title{
Apresentação Violências, América Latina: a disseminação de formas de violência e os estudos sobre conflitualidades
}

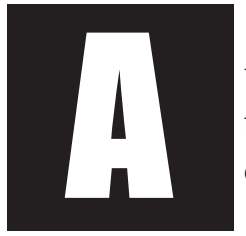

reconstrução sociológica da disseminação das diferentes formas de violência nas sociedades latino-americanas contemporâneas constitui o tema central deste dossiê Violências, América Latina.

A observação de um fato social - as violências disseminadas pelo espaço social - possibilita a construção de um objeto sociológico, mediante a ótica espaço-temporal da conflitualidade, tecendo uma explicação sociológica da violência, a partir da experiência latino-americana mas com alcance teórico para várias sociedades contemporâneas, pois nos encontramos diante da mundialização da violência e da injustiça ${ }^{1}$.

Este dossiê representa uma ampliação dos temas analisados nos estudos sobre conflitualidades, publicados no primeiro número da Revista Sociologias. Sugeríamos, naquela oportunidade, que

uma sociologia das conflitualidades, no tempo atual, deve ser situada no contexto dos efeitos do processo de globalização da sociedade e da economia, os quais produzem transformações na estrutura e no espaço social das diversas regiões do planeta, desencadeando

*Doutor de Estado (Université de Paris - Nanterre); Professor Titular do Departamento e do Programa de Pós-graduação em Sociologia e Diretor do Instituto de Filosofia e Ciências Humanas da Universidade Federal do Rio Grande do Sul. 1 TAVARES DOS SANTOS, José Vicente. The Worldization of Violence and Injustice. In: Current Sociology. London, ISA International Sociological Association/SAGE, v. 50, n. 1, January 2002, p. 123-134. 
novos conflitos sociais e novas formas de conflitualidades ${ }^{2}$.

No início do Século XXI, a questão das conflitualidades - das formas de violência, das metamorfoses do crime, da crise das instituições de controle social e dos conflitos sociais - configura-se pela emergência de novas modalidades de ação coletiva, com lutas sociais protagonizadas por outros agentes sociais e diferentes pautas de reivindicações.

Estamos em presença de um social heterogêneo, no qual nem indivíduos nem grupos parecem reconhecer valores coletivos. Esse contexto dá origem a múltiplos arranjos societários, a múltiplas lógicas de condutas. Predominando tal situação é válido falar em sociedade fragmentada, plural, diferenciada, heterogênea (Grossi Porto).

Conformam-se novas questões sociais mundiais, seja porque "os processos de transformação pelas quais vem passando o trabalho afetam sua característica de integração social, com uma configuração fundamentalmente marcada pela fragmentação" (Grossi Porto), seja pela expansão dos fenômenos da violência difusa, para cuja explicação poderia ser útil uma microfísica da violência ${ }^{3}$.

Retomamos, para apresentar estes trabalhos, uma definição anterior de violência difusa ${ }^{4}$ : as diferentes formas de violência presentes em cada um dos conjuntos relacionais que estruturam o social podem ser explicadas se compreendermos a violência como um ato de excesso, qualitativamente distinto, que se verifica no exercício de cada relação de poder presente nas

2 TAVARES DOS SANTOS, José Vicente. As conflitualidades como um problema sociológico contemporâneo. In: Revista Sociologias - Dossiê "Conflitualidades". Porto Alegre, PPG-Sociologia do IFCH - UFRGS, Porto Alegre, ano 1, n. 1, janeiro-junho de 1999, p. 10-13.

3 TAVARES DOS SANTOS, José Vicente. Microfísica da Violência, uma questão social mundial. In: Ciência e Cultura. Revista da SBPC - Sociedade Brasileira para o Progresso da Ciência, São Paulo, Ano 54, n. 1, julho de 2002, p. $22-24$ (Núcleo temático: Violência).

4 TAVARES DOS SANTOS, José Vicente. A violência como dispositivo de excesso de poder. In: Revista Sociedade \& Estado. Brasília, UnB, v. 10, n. 2, julho-dezembro 1995, p. 281-298; TAVARES DOS SANTOS, José Vicente (ed.). Violências em tempo da globalização. São Paulo: Hucitec, 1999. 
relações sociais de produção do social. A idéia de força, ou de coerção, supõe um dano que se produz em outro indivíduo ou grupo social, seja pertencente a uma classe ou categoria social, a um gênero ou a uma etnia, a um grupo etário ou cultural. Força, coerção e dano, em relação ao outro, enquanto um ato de excesso presente nas relações de poder - tanto nas estratégias de dominação do poder soberano quanto nas redes de micropoder entre os grupos sociais - caracteriza a violência social contemporânea.

Os textos incluídos neste dossiê analisam vários países (Argentina, Brasil, Colômbia, Uruguai e Venezuela), expressando um elenco de questões substantivas, emergentes de pesquisas tanto no espaço urbano - Caracas, Maracaibo, Bogotá, Buenos Aires, Brasília e São Paulo - quanto no espaço rural - da Argentina, Uruguai e Brasil - para o futuro da transformação social das sociedades latino-americanas. Tais questões, esboçando traços de uma outra explicação sociológica das conflitualidades na América Latina, podem ser assim formuladas: quais as formas de violências que predominam na América Latina no início do Século XXI? Quais as origens sociais, econômicas e políticas das violências? Como se conforma a crise do sistema de Justiça Penal? Quais as experiências inovadoras e as lutas sociais pela cidadania que se configuram atualmente na América Latina? Qual a matriz disciplinar dos estudos sociológicos sobre as conflitualidades?

\section{Quais as formas de violências que predominam na América Latina no início do Século XXI?}

O aumento dos processos estruturais de exclusão social pode vir a gerar a expansão das práticas de violência como norma social particular, vigente em vários grupos sociais enquanto estratégia de resolução de conflitos, ou meio de aquisição de bens materiais e de obtenção de prestígio social, significados esses presentes em múltiplas dimensões da violência social e política contemporânea ${ }^{5}$.

5 TAVARES DOS SANTOS, José Vicente. As conflitualidades como um problema sociológico contemporâneo. In: Revista Sociologias - Dossiê "Conflitualidades". Porto Alegre, PPG-Sociologia do IFCH - UFRGS, Porto Alegre, ano 1, n. 1, janeiro-junho de 1999, p. 10-13. 
Em primeiro lugar, verifica-se a realização de uma violência estrutural (Adorno), decorrente de características da estrutura social e econômica dos países latino-americanos desde a década de 1990: concentração da propriedade da terra, efeitos das políticas de ajuste estrutural, corrupção, concentração de renda, desigualdade social.

Em segundo lugar, aumentou a violência criminal urbana, seja pelas ações do crime organizado, em especial o tráfico de drogas e o comércio ilegal de armas, seja pela difusão do uso de armas de fogo, ambos provocando uma maior letalidade nos atos delitivos. Essa é, porém, muito mais "uma violência de pobres contra pobres", pela qual se identifica uma "vitimização dos pobres" (Briceño-León). Ao mesmo tempo, está ocorrendo uma alteração nos autores de delitos, ou seja, nos "grupos ligados a práticas ilegais, em especial o roubo, que apresentam como aspecto notório a contingência e a espontaneidade, em suma, a desprofissionalização das práticas delitivas (Pegoraro).

A situação em Bogotá parece ser um tipo extremo na América Latina, capital na qual pode se concluir que: 1) as mortes violentas estão concentradas em alguns focos; 2) a violência instrumental resulta em um maior número de mortes; 3 ) existe uma convergência entre os focos de violência e a presença de estruturas criminais associadas a mercados ilegais (Llorente et alii).

Entretanto, também na sociedade brasileira houve a disseminação da violência criminal, com uma mudança das formas de delitos e de violência:

a) o crescimento da delinqüência urbana, em especial dos crimes contra o patrimônio (roubo, extorsão mediante seqüestro) e de homicídios dolosos (voluntários); b) a emergência da criminalidade organizada, em particular em torno do tráfico internacional de drogas que modifica os modelos e perfis convencionais da delin- 
qüência urbana e propõe problemas novos para o direito penal e para o funcionamento da justiça criminal; c) graves violações de direitos humanos que comprometem a consolidação da ordem política democrática; d) a explosão de conflitos nas relações intersubjetivas, mais propriamente conflitos de vizinhança que tendem a convergir para desfechos fatais (Adorno).

Em terceiro lugar, foram investigadas as violências nos conflitos sociais agrários, as quais se manifestam como forma de dominação que se exerce pelo silêncio temeroso ou como violência política contra os agentes das lutas sociais pela posse ou propriedade da terra, algumas vezes mediante o "sistema de pistolagem" (Barreira). Por outra parte, estão ativas as ações de protesto contra a expropriação e a exploração que sofrem os pequenos produtores rurais e os trabalhadores agrícolas: "houve um forte processo de concentração da propriedade da terra e de expulsão de produtores familiares, o qual constituiu umas das formas de violência social mais notória no meio rural" (Piñeiro). A expansão da conflitualidade social deu-se por

novos atores (mulheres em um mundo rural fortemente patriarcal, povos indígenas); novos repertórios de ações; novas demandas e os intentos de construção de redes horizontais entre eles e com os movimentos camponeses da América Latina, [o que] permite sustentar que estamos diante da presença de um novo tipo de protesto social (Giarraca).

A violência estrutural expressa-se, ainda, pela exploração e precarização nas relações de trabalho rural, tal como na sociedade uruguaia: "no meio rural as próprias relações sociais de produção e os mecanismos de dominação exercem uma violência difusa sobre os trabalhadores rurais e sobre os produtores familiares" (Piñeiro). 


\section{Quais as origens sociais, econômicas e políticas das Violências?}

Todos os autores salientam a desigualdade social como uma das origens estruturais das violências, enfatizando-se a hipótese de que "o empobrecimento e a desigualdade, e não a pobreza, são os elementos que originam a violência urbana" (Briceño-León). Deve-se adicionar, enfaticamente, o processo de segregação no espaço urbano:

Registros de mortes violentas revelam maior incidência nos bairros que compõem a periferia urbana onde são precárias as condições sociais de existência coletiva e onde a qualidade de vida é acentuadamente degradada. Há fortes evidências de que o risco de ser vítima de homicídio é significativamente superior entre aqueles que habitam áreas, regiões ou bairros com déficits sociais e de infra-estrutura urbana, como aliás sugerem os mapas de risco elaborados para diferentes capitais brasileiras (Adorno).

Desigualdade social e segregação urbana produzem uma exclusão social, marcada pelo desemprego, pela precarização do trabalho, salários insuficientes e por deficiências do sistema educacional.

Agravam-se tais condições de exclusão pela trágica condição da juventude na América Latina. As maiores vítimas mas também a maior proporção de autores de atos violentos estão entre os homens jovens:

Em todo o país, o alvo preferencial dessas mortes compreende adolescentes e jovens adultos masculinos, em especial procedentes das chamadas classes populares urbanas, tendência que vem sendo observada em inúmeros estudos sobre mortalidade por causas violentas. (...) Aumentou a proporção de adolescentes representados na criminalidade violenta. No primeiro período, era menor a proporção de crimes violentos 
cometidos pelos adolescentes face à proporção de crimes violentos cometidos na população em geral. No segundo período, esta tendência se inverte (Adorno).

Muitas vezes, os atos de violência representam "estratégias de sobrevivência" dos jovens: "A chamada violência juvenil atual pode ser vista como uma das estratégias de reprodução ou de sobrevivência de setores excluídos em termos educativos e laborais, ou seja, da existência que se supõe outorgue identidade aos jovens" (Pegoraro). Acentua-se a situação de vulnerabilidade dos jovens quando "aqueles em fase de escolarização não apenas não assistem a escola como tampouco estão inseridos no trabalho" (Pegoraro).

As análises sobre Caracas e Buenos Aires foram desenvolvidas a partir da hipótese de que o desnível entre a oferta de mercadorias e a capacidade da demanda produz uma "insatisfação de expectativas nas gerações de pobres que já nasceram nas cidades", ou seja, "um abismo entre o que se aspira como qualidade de vida e as possibilidades reais de alcançá-la" (Briceño-León). O enfoque estrutural "localiza nas classes populares e pobres uma carência de bens materiais que se expressa na pobreza, na desigualdade, na marginalização, exclusão e desemprego; por conseqüência, esta carência de bens materiais os leva a cometer delitos" (Pegoraro).

\section{Como se conforma a crise do sistema de Justiça Penal?}

Na América Latina,

a crise do Welfare State de finais dos anos 70 e a aplicação das políticas neoliberais, produziu, também, uma quebra do controle social informal que realizavam a família, a escola, os clubes de bairro, a Igreja, as bibliotecas vicinais, instituições que tinham uma forte capacidade de socialização dos indivíduos em torno de valores como a solidariedade, a piedade, a honestida- 


$$
\text { de e o trabalho (Pegoraro). }
$$

Porém, o sistema de Justiça Penal não conseguiu substituir tais controles sociais. A crise das polícias é marcante, em todos os países repetindo-se a violência policial, a corrupção, a ineficácia na prevenção das violências e a ineficiência na investigação criminal (Adorno \& Cardia).

Existe uma evidente crise do sistema de justiça penal, pois o acesso à Justiça é precário, a seletividade orienta os processos penais ${ }^{6}$, e a normatividade da lei não se efetiva:

a lei penal (e sua função preventiva) está neutralizada por uma realidade social composta por desigualdades crescentes e moral débil, mas também porque a ameaça dos castigos e sua aplicação não chegam a evitar as demandas compulsivas por consumo da sociedade de mercado (Pegoraro).

Flagrante também é a crise das prisões, evidenciando sua ineficácia na dissuasão das condutas delitivas (Pegoraro) bem como a permanência da reincidência criminal, sobre a qual foram investigadas três dimensões:

a) variáveis biográficas ou socioeconômicas; b) tipo de ofensa, e c) condições de prisão. A dimensão biográfica explica 32\% da reincidência, o tipo de crime explica 9\% adicional da reincidência, e as condições de prisão explicam 16\% adicional, sugerindo ampla margem de política prisional na redução da reincidência (Fandiño).

Uma das conseqüências da assinalada crise do sistema de justiça penal é a recorrente impunidade:

No Brasil, tudo parece indicar que as taxas de impunidade sejam mais elevadas para crimes que constituem graves violações de direitos humanos, tais como: homi-

6 TAVARES DOS SANTOS, José Vicente. O saber do crime, a noção de violência e a seletividade penal. In: Delito y Sociedad - Revista de Ciencias Sociales. Buenos Aires, Universidad Nacional del Litoral, Ano 9, n. 14, 2000, p. 94-106. 
cídios praticados pela polícia, por grupos de patrulha privada, por esquadrões da morte e/ou grupos de extermínio, ou ainda homicídios consumados durante linchamentos e naqueles casos que envolvem trabalhadores rurais e lideranças sindicais. Do mesmo modo, parecem altas as taxas de impunidade para crimes do colarinho branco cometidos por cidadãos procedentes das classes médias e altas da sociedade (Adorno).

Outro efeito da crise reside na privatização do controle social, ora pelo sistema de pistolagem (Barreira), ora pela segurança privada:

Tanto o serviço informal de segurança privada como o cercamento de espaços residenciais e a inscrição em organizações que oferecem a segurança de bens, podem ser considerados como mecanismos de autodefesa, implementados pelos setores médios da sociedade (...) com o objetivo de garantir uma certa proteção (Romero Salazar).

Alarga-se, enfim, o recurso a formas violentas e ilegais de solução de conflitos: "... a grande maioria da população urbana depende de guardas privados não profissionalizados, se apóia perversamente na 'proteção' oferecida por traficantes locais ou procura resolver suas pendências e conflitos por conta própria" (Adorno). Estudando as trajetórias de pistoleiros e de "vingadores", Barreira indica a legitimação da particularização do controle social:

Podemos dizer que existe um substrato de realismo social nas trajetórias dos pistoleiros, carregadas de valores de vingança, valentia e coragem. São valores que oferecem uma base de legitimidade social nas ações dos pistoleiros que têm sentido em uma sociedade onde existe uma certa aceitação ou demonstração de simpatia pelas resoluções violentas de conflitos, uma be- 
nevolência sobre os crimes de honra, uma tolerância sobre a atuação dos justiceiros e uma indiferença sobre os massacres de trabalhadores rurais. (...) Os pistoleiros aparecem, então, como vingadores, restituidores da justiça de outrem, através de soluções violentas (Barreira).

\section{Quais os efeitos dos meios de comunicação na disseminação das Violências?}

Tais manifestações da violência urbana revelam que, na vida cotidiana, realiza-se uma condensação entre "mal estar da pósmodernidade"7, violência simbólica, "sentimento de insegurança" (Pegoraro) e sentimentos de medo: "A violência apresenta, além dos custos de dor e sofrimento humano, um componente de mal estar psicológico derivado do medo que inspira e um impacto econômico, pelas vítimas e custos reais, e também pelos gastos e perdas que a prevenção e o medo obrigam" (Briceño-León).

Vários Autores, neste dossiê, analisam a consciência coletiva marcada pela violência e pelo medo (Grossi Porto, Romero Salazar). Estamos vivendo em um horizonte de representações sociais da violência para cuja disseminação contribuem os meios de comunicação de massa, produzindo a dramatização da violência e difundindo a "espetacularização" do crime violento, enquanto um efeito da violência simbólica exercida pelo "campo

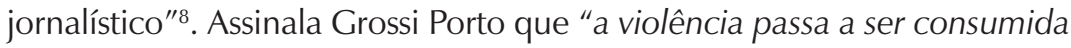
num movimento dinâmico em que o consumo participa também do processo de sua produção, ainda que como representação".

7 BAUMAN, Z. O mal-estar da pós-modernidade. Rio de Janeiro: Jorge Zahar, 1998. 8 BOURDIEU, Pierre. Sur la télévision. Paris: Líber, 1996; TEIXEIRA, Alex Niche. A Espetacularização do Crime Violento pela Televisão: o caso do Programa Linha Direta. Porto Alegre, Programa de Pós-graduação em Sociologia do Instituto de Filosofia e Ciências Humanas da Universidade Federal do Rio Grande do Sul, Dissertação de Mestrado, 2002. 


\section{Quais as experiências inovadoras e as lutas sociais pela cidadania que se configuram na América Latina no início do Século XXI?}

Estamos em um tempo de ações coletivas mundializadas: "protestos rurais", formas de organização das populações urbanas e de lutas sociais contra as violências. Observa-se, por outro lado, experiências inovadoras nas Polícias:

... modelos de integração de uma política de segurança pública que unificou o seu comando no estado e tem buscado a integração das ações policiais em toda a estrutura de poder dos aparelhos policiais, apesar das diferenças de atribuições e interesses, das disputas e rusgas existentes entre as duas polícias (Mota Brasil e Abreu).

Mais ainda, se sugere que melhorias no sistema prisional poderiam ter feitos na redução da reincidência criminal (Fandiño).

Visualiza-se, de modo largo, a construção de um modelo de segurança do cidadão e da cidadã, composto por políticas sociais, por projetos sociais preventivas, protagonizados pelas administrações públicas, pelo mundo associativo, pelo terceiro setor, pelas escolas: trata-se da emergência da planificação emancipatória no campo da segurança, enfatizando a mediação de conflitos e a pacificação da sociedade contemporânea ${ }^{9}$. Assim, pode-se observar, em Bogotá,

que se sugere precisamente a recuperação de um certo nível de segurança, particularmente através de atividades focalizadas de controle, o qual, uma vez atingido, permitiria incrementar a eficácia das ações em outros campos substantivos para a prevenção do crime -

9 TAVARES DOS SANTOS, José Vicente. Novas questões sociais mundiais, projetos sociais e culturais e a planificação emancipatória. In: Revista Humanas. Porto Alegre, IFCH da UFRGS, v. 24, n. 1-2, janeiro-dezembro de 2001, p. 163-185. 
a família, as comunidades, as escolas e a força de trabaIho (Llorente et alii).

Isso significa uma perspectiva de desenvolver um processo civilizador de superação das formas de violência e de ampliação da cidadania, desenhando uma agenda pública sobre o direito à segurança de cada cidadão e cidadã.

\section{Qual a matriz disciplinar dos estudos sociológicos sobre as conflitualidades?}

No plano teórico, é oportuno reiterar a observação de que se desenvolve "uma abordagem inovadora acerca das várias redes de dominação e de violência presentes nas formações sociais contemporâneas, indicando, ainda, novas possibilidades teóricas para sua compreensão sociológica"10.

A novidade analítica que se revela nos estudos componentes deste dossiê reside em uma perspectiva da complexidade, sintetizada por Morin:

O método da complexidade pede-nos que pensemos sem nunca encerrar os conceitos, que quebremos as esferas fechadas, que restabeleçamos as articulações entre o que está desconjuntado, que tentemos compreender a multidimensionalidade, que pensemos com a singularidade, com a localização, com a temporalidade, que não esqueçamos nunca as totalidades integradoras. (...) A totalidade é simultaneamente verdade e não-verdade, é isso a complexidade: a conjunção de conceitos que se combatem entre $s i^{11}$.

Tal perspectiva epistemológica expressa-se na crítica a algumas abordagens clássicas sobre o tema das conflitualidades, e na formulação de

10 TAVARES DOS SANTOS, José Vicente. As conflitualidades como um problema sociológico contemporâneo. In: Revista Sociologias - Dossiê "Conflitualidades". Porto Alegre, PPG-Sociologia do IFCH - UFRGS, Porto Alegre, ano 1, n. 1, janeiro-junho de 1999, p. 10-13.

11 MORIN, Edgar. Ciência com Consciência. Portugal: Europa-América, 1994, p. 150; MORIN, Edgar. La Méthode III: La connaissance de la connaissance. Paris: Seuil, 1986 (Ed. portuguesa: Europa-América). 
novos instrumentos interpretativos, confirmando recente percepção de Adorno \& Cárdia de que

vêm avançando rapidamente os estudos e pesquisas que procuram decifrar a violência - as percepções, os fatos e acontecimentos; o impacto sobre a justiça; as diversas formas e significados da violência para os distintos grupos sociais; as relações entre cidadania, segregação urbana e violência - na sociedade brasileira ${ }^{12}$.

A publicação de um respeitável e sucessivo elenco de revisões do "estado da arte" evidencia a maturidade deste campo científico na sociologia brasileira e latino-americana ${ }^{13}$.

Parece estarmos vivenciando um momento de transição paradigmática ${ }^{14}$ cuja ruptura epistemológica consiste no denominado pós-estruturalismo, no qual se inclui a crítica do marxismo ortodoxo, do funcionalismo e do estruturalismo. Em outras palavras,

a reprodução e a transformação social se abordou desde a reflexão acerca das condições que habilitam a formação de atores capazes de intervir no estado das coisas, capazes de produzir novos sentidos. Foi ressignificado o conceito de estrutura, mostrou-se que, como todo sistema de significantes, os mundos sociais são suscetíveis de compreensões e não de explicações e predições (Giarraca).

\footnotetext{
12 ADORNO, Sérgio \& CARDIA, Nancy. Núcleo temático: Violência - Nota de apresentação. In: Revista Ciência e Cultura SBPC - Sociedade Brasileira para o Progresso da Ciência, São Paulo, Ano 54, n. 1, julho de 2002, p. 20-21.

13 As revisões publicadas foram: BRETAS, Marcos Luiz. O Crime na Historiografia Brasileira. In: BIB. Rio de Janeiro, n. 32, 1991, p. 49-61; TAVARES DOS SANTOS, J.V. Crítica da Sociologia Rural e a construção de uma outra sociologia dos processos sociais agrários. In: Ciências Sociais Hoje. São Paulo: ANPOCS/Vértice, 1991, p. 13-51; ADORNO, Sérgio. A criminalidade urbana violenta: um recorte temático. In: BIB. Rio de Janeiro: ANPOCS, n. 35, 1993, p. 3-24; ZALUAR, Alba. Violência e Crime. In: MICELI, S. (org.). O que ler na ciência social brasileira. São Paulo: ANPOCS/Sumaré, 1999, p. 13-107; BRUMER, Anita \& TAVARES DOS SANTOS, J.V. Estudos agrários no Brasil: modernização, violência e lutas sociais (desenvolvimento e limites da Sociologia Rural no final do Século XX). In: PIÑEIRO, Diego (org.). 30 Años (anos) de Sociología Rural en (na) América Latina. Montevideo, Uruguay: ALASRU / SBS, 2000, p. 33-69; KANT DE LIMA, Roberto; MISSE, Michel; MIRANDA, Ana Paula Mendes. Violência, Criminalidade, Segurança Pública e Justiça Criminal no Brasil: uma bibliografia. In: BIB - Revista Brasileira de Informação Bibliográfica em Ciências Sociais. Rio de Janeiro, n. 50, 2o semestre de 2000, p. 45-123; SPOSITO, Marília Pontes. Um breve balanço da pesquisa sobre violência escolar no Brasil. In: Revista Educação e Pesquisa. São Paulo: Fac. De Educação da USP, v. 27, n. 1, janeiro-junho de 2001.
} 
Reflexões que lembram um enunciado anterior de Adorno sobre o esgotamento dos grandes modelos de interpretação teórica:

a referência privilegiada às estruturas cede terreno à referência aos atores sociais; a noção de totalidade, que até então consistia em garantia de compreensão da sociedade, desfaz-se diante das evidências: o social (...) é um fervilhar de particularismos, sem pontos fixos de contato, sem horizontes previamente definidos, no qual os sentimentos são fugazes, perde-se o significado do tempo histórico, abala-se a fé no progresso ${ }^{15}$.

A matriz teórica dos estudos sobre as conflitualidades vem sendo composta a partir de uma abordagem geral que se nutre dos clássicos do pensamento sociológico. Em Marx, foram buscadas análises sobre o modo de produção do social, as relações de classe, as contradições estruturais e as análises históricas do conflito social e do papel da violência na História.

Em Weber, retomaram-se os textos acerca do Poder do Estado - a noção de "monopólio legítimo da violência" - da relação entre dominação e legitimação, e sobre a burocracia; também foram úteis as indicações acerca dos conflitos sociais, "os conflitos dos deuses" e a "gaiola de ferro da burocracia"16.

Em Durkheim, foram localizadas as contribuições sobre a divisão social do trabalho, a relação entre norma e conflito, o conceito de anomia, o estudo sobre o suicídio e a concepção do "crime" como fato social normal.

Em Elias, foram fundamentais os livros sobre o "processo civilizatório" e acerca da violência como prática social ${ }^{17}$.

14 SOUSA SANTOS, Boaventura. A crítica da razão indolente: contra o desperdício da experiência. São Paulo: Cortez, 2000. 15 ADORNO, Sérgio. Natureza, História e Cultura: repensando o social - Apresentação. In: ADORNO, Sérgio (org.). Natureza, História e Cultura: repensando o social. Porto Alegre: Editora da Universidade-UFRGS / SBS, 1993, p. 77-84 (Cadernos de Sociologia, Programa de Pós-graduação em Sociologia da UFRGS, vol. 4, número especial), p. 8.

16 GROSSI PORTO. Maria Stela. Entre a política e a religião: caminhos da contribuição weberiana à análise da violência. Revista Sociologias. Porto Alegre, PPG-Sociologia do IFCH - UFRGS, Número 1, setembro de 1999, Dossiê "Conflitualidades", p. 14-33.

17 ELIAS, Norbert \& DUNNING, Eric. Sport et civilisation: la violence maîtrisée. Paris: Fayard, 1986 (ed. portuguesa: DIFEL); ELIAS, Norbert. O processo civilizador - uma história dos costumes. RJ:, Jorge Zahar, v. I, 1990; ELIAS, Norberto. O processo civilizador - formação do Estado e Civilização. RJ, Jorge Zahar, v. II, 1993; ELIAS, Norbert. Os alemães: a luta pelo poder e a evolução do habitus nos séculos XIX e XX. Rio de Janeiro: Jorge Zahar, 1997. 
Tais elementos, entretanto, foram absorvidos a partir da novidade histórica das ciências sociais no período de crise da modernidade, ou seja, desde o novo "modo de interpretar a História" construído pela obra de Michel Foucault. As fontes inspiradoras foram menos os trabalhos da "arqueologia do saber" e mais aqueles publicados a partir de "Vigiar e Punir", de 1976, e a retomada da "História da Loucura", assim como os ensinamentos da "História da Sexualidade".

Em outras palavras, os estudos sobre as conflitualidades expressam a postura epistemológica da "genealogia do poder-saber", ponto de vista inovador que possibilitou uma releitura dos clássicos bem como a incorporação dos conceitos de "sociedade disciplinar", "dispositivo poder-saber", "governabilidade" e "biopolítica"18.

Mais recentemente, as interpretações de Pierre Bourdieu sobre a violência simbólica tiveram relevo para explicar os "sentimentos de insegurança" e a influência dos meios de comunicação nos fenômenos de violência $^{19}$. Enfim, o deslocamento do olhar sociológico para a sociedade global possibilitou a passagem para uma sociologia das conflitualidades no processo da mundialização ${ }^{20}$.

18 ADORNO, Sérgio. “Conflitualidade e violência: reflexões sobre a anomia na contemporaneidade. Tempo Social, Revista de Sociologia da USP. São Paulo, v. 10, n. 1, p. 19-47; PEGORARO, Juan. Inseguridad y violencia en el marco del control social. In: TAVARES DOS SANTOS, José Vicente (ed.). Violências em tempo da globalização. São Paulo: Hucitec, 1999, p. 201-228; RIBEIRO, Iselda. Justiça. Há alguma? Conflitualidade, justiça e poder em Michel Foucault. In: Revista Sociologias. Porto Alegre, PPG-Sociologia do IFCH - UFRGS, n. 1, setembro de 1999, Dossiê "Conflitualidades", p. 340-351; GHIRINGHELLI DE AZEVEDO, Rodrigo. Pluralismo Jurídico e Direitos Humanos: Uma difícil e necessária equação na transição pós-moderna. In: Revista Sociologias. Porto Alegre, PPG-Sociologia do IFCH - UFRGS, n. 1, setembro de 1999, Dossiê "Conflitualidades", p. 96-120; RIELLA, Alberto. Violência y control social: el debilitamiento del orden social moderno". In: Revista Sociologias. Porto Alegre, PPG-Sociologia do IFCH - UFRGS, n. 1, setembro de 1999, Dossiê "Conflitualidades", p. 122-145; TAVARES DOS SANTOS, José Vicente. Michel Foucault, um pensador das redes de poder e das lutas sociais. In: Revista Educação, Subjetividade e Poder. Porto Alegre, NESPE/ PPG - Educação da UFRGS, Ed. UNIJUI, janeiro - junho de 1996, n. 3, p. 7-16.

19 BOURDIEU, Pierre (ed.) La Misère du Monde. Paris: Seuil, 1993 (Ed. Brasileira: Vozes); BOURDIEU, Pierre. La domination masculine. Paris: Seuil, 1998.

20 ARRIGHI, Giovanni \& SILVER, Beverly J. Caos e Governabilidade no Moderno Sistema Mundial. Rio de Janeiro: Contraponto / Editora da UFRJ, 2001; BAUMAN, Zygmunt. Em busca da Política. Rio de Janeiro: Jorge Zahar, 2000; BAUMAN, Zygmunt. O mal-estar da pós-modernidade. Rio de Janeiro: Jorge Zahar, 1998; CASTEL, R. La métamorphoses de la question sociale. Paris: Fayard, 1995 (Ed. Brasileira: Vozes); CHESNAIS, Jean Claude. Histoire de la violence en Occident de 1800 à nos jours. Paris: Laffont, 1981; GIDDENS, Anthony. As conseqüências da modernidade. São Paulo: Ed. da UNESP, 1991; GIDDENS, Anthony. Mundo em descontrole: o que a globalização está fazendo de nós. Rio de Janeiro: Record, 2000; IANNI, Octavio. A Era do Globalismo. Rio de Janeiro: Civilização Brasileira, 1996; IANNI, Octávio. A Sociedade Global. Rio de Janeiro: Civ. Brasileira, 1992; JAMESON, Fredric. Pós-modernismo: a lógica cultural do capitalismo tardio. São Paulo: Ática, 1996. 
No conjunto dos textos, pode-se perceber ora uma flexibilização no uso de conceitos clássicos do pensamento sociológico, ora a elaboração de novas noções interpretativas, revelando uma dimensão fecunda dos estudos sobre conflitualidades.

A flexibilização no uso de conceitos aparece, por exemplo, na referência à hipótese de Merton sobre a disparidade entre a oferta de mercadorias e a capacidade da demanda: "a conduta anômala pode ser considerada, desde o ponto de vista sociológico, como um sintoma da dissociação entre as aspirações culturais prescritas e os caminhos socialmente estruturais para chegar a tais aspirações" 21 . O que se passa agora é que tal disparidade é estrutural, representada pela noção de desigualdade e de exclusão social (Briceño-León; Pegoraro). Também, reverberam ecos de Chicago, pois tanto se faz uma crítica de algumas idéias, como a de "gangue", da Escola de Chicago (Pegoraro), quanto se incorpora a cartografia do crime e da violência, tentando identificar a distribuição diferencial no espaço desses fenômenos (Adorno \& Cárdia, Llorente et alii; Giarraca).

No que tange à elaboração de novas abordagens explicativas, houve, em vários textos, a incorporação de conceitos do "interacionismo simbólico" (Pegoraro) para a análise da violência institucional e do comportamento desviante ${ }^{22}$ e da criminologia crítica da "modernidade tardia"23. Por outro lado, existe a alteração do conceito de "novos movimentos sociais" para "ações de protesto" (Giarraca) e o relevo dado aos processos de superação das violências e de construção de uma sociedade democrática com cidadania ampliada e concretizada.

Em suma, os estudos sobre sociologia da conflitualidade denotam um vigor investigativo e interpretativo capaz de nutrir uma forte agenda de pesquisas para a sociologia latino-americana.

21 MERTON, Robert K. Teoria y estructura sociales. México, FCE, 1964, p. 143.

22 VISCARDI, Nilia Viscardi. Disciplinamiento, control social y estigma: tres conceptos para una sociología del conflito. In: Revista Sociologias. Porto Alegre, PPG-Sociologia do IFCH - UFRGS, n. 1, setembro de 1999, Dossiê "Conflitualidades", p. 168198.

23 YOUNG, Jock. The Exclusive Society. London: Sage, 1999; TAYLOR, lan. Crime in Context. Cambridge: Polity Press, 1999. 
No tempo infinito da paciência, do diálogo e da mediação dos conflitos sociais, no fragmentado espaço social da América Latina, a disseminação das violências também vem produzindo, para além do desencanto, novas relações de sociabilidade e outras formas de controle social, na esperança, compartilhada pelos autores, de pacificar a sociedade, respeitando as diferenças, reduzindo as iniqüidades e as injustiças e reconhecendo a dignidade humana de todos os cidadãos e cidadãs latino-americanos.

Provavelmente, muito mais haverá - nesses estudos sociológicos elaborados mediante a interação entre construtos teóricos e realidades histórico-sociais - de argúcia analítica e de inventividade intelectual, cuja descoberta será obra e arte da sensibilidade dos leitores que desejarem percorrer esta aventura sociológica. 